\title{
Desenho de moda: uma análise sobre imaginação e criatividade à luz da teoria vigotskiana
}

\author{
Fashion design: an analysis of imagination and creativity in light of the Vygotskian \\ theory
}

LOS, Vivian Andreatta; Mestre em Educação; FURB

vlos@ifsc.edu.br

SCHROEDER, Edson; Doutor em Educação; UFSC

ciencia.edson@gmail.com

BABINSKI, Valdecir Júnior; Graduado em Moda; UDESC

vj.babinski@gmail.com

\section{Resumo}

Imaginação e criatividade são fundamentais para futuros estilistas e designers. O próprio desenvolvimento da linguagem imagética, apurada através do desenho de moda enquanto ainda estudantes, não acontece longe do campo da fantasia, da memorização e das experiências vivenciadas. A estética e o design que provém desta linguagem é, então, forma do potencial criativo de cada um. Neste artigo pretende-se explorar a relação que estipula a perspectiva vigotskiana ao criar e ao desenhar através do uso da imaginação e da criatividade. Com abordagens que vão desde a infância, passando pela adolescência e culminando na vida adulta e profissional, as contribuições de Vigotski são analisadas, aqui, em consoante com a prática pedagógica realizada no grupo de pesquisa "Ilustração de moda avançada", do qual participaram dois professores e dez estudantes dos cursos técnicos de Produção e Design de Moda e de Vestuário, do Instituto Federal de Santa Catarina, Câmpus Jaraguá do Sul.

Palavras Chave: criatividade; imaginação; desenho de moda.

\begin{abstract}
Imagination and creativity are crucial to future designers. The very development of imagetic language does not happen far from the field of fantasy, memorization and experience; in addition, this development is refined during the period designers are training to become designers. Aesthetics and design that comes from imagetic language then becomes a form of creative potential of each person. In the present paper, we adopt a Vygotskian perspective in order to investigate how drawing relates to creation through use of imagination and creativity. The pedagogical practices carried out by the research group "Illustration of advanced fashion", draws upon Vygotsky's contributions, which range from childhood, adolescence to adulthood and professional life. The group comprises two teachers and ten students of the technical courses of Fashion Design and Clothing at IFSC (Instituto Federal de Santa Catarina, IFSC - Jaraguá do Sul).
\end{abstract}

Keywords: creativity; imagination; fashion design. 


\section{Introdução}

O artigo que se apresenta a seguir constitui-se como resultado dos estudos do Grupo de pesquisa "Ilustração de moda avançada", do Instituto Federal de Santa Catarina, câmpus Jaraguá do Sul, unidade Centro. O grupo, cujo registro interno da instituição é dado por 61FCPROP2016, compõe-se por dois professores formados na área de moda, que atuam nos cursos: técnico em de Produção e Design de Moda; e técnico em Vestuário, da supracitada instituição, e de mais dez estudantes de ambos os cursos.

O grupo de pesquisa fora formado com o intuito de estudar novas metodologias, assim como novas ferramentas para a estimulação da criatividade envolvida na construção de desenhos de moda. Técnicas de ilustração diversificadas; experimentações em termos de estéticas e de materiais; e discussões teóricas sobre o desenvolvimento do desenho de moda também foram pautas no decorrer dos encontros realizados.

Os resultados obtidos, além de potencializarem a aproximação entre os estudantes e o desenho de moda - e, ainda, entre os mesmos e a pesquisa científica, decorreram em coleções de desenhos construídos, um a um, com base em temas específicos. Os temas, escolhidos a cada encontro quinzenal surgiram de propostas realizadas pelos próprios estudantes que, no espaço entre um encontro e outro, pesquisavam assuntos, pautas e referências sobre a moda e o design, o que era compilado e apresentado, rapidamente, para os demais. Coube, então, aos professores do grupo provocarem os estudantes para um olhar mais atento sobre os temas que podem ser sugeridos para o desenho de moda pelos contextos vivenciados ou pesquisados.

Tais temas, coletados pelos estudantes segundo seus próprios interesses, eram acolhidos pelo grupo de pesquisa, que buscava discutir abordagens criativas para os mesmos. Ofereciam-se, ainda, perspectivas dos temas acolhidos sob um olhar da moda, que, por si só, já apresenta temas consagrados ou clássicos - que, conforme desejo do grupo, eram evitados. Segundo Renfrew e Renfrew (2010, p. 53),

É possível agrupar ou identificar temas comuns na moda - aqueles que influenciam o processo criativo no desenvolvimento de uma coleção ou o modo como escolhemos usar as roupas. Influências recorrentes incluem trajes típicos, esportes, uniformes de trabalho, exército, política e futurismo.

Com a intenção de fugir aos temas comuns da moda, e após as discussões e apresentações, o tema específico e, portanto, final, era escolhido através da ferramenta de brainstorming. Para Morris (2009, p. 14), "um bom começo para o processo investigativo é fazer uma lista de palavras associadas ao tema. Isso é conhecido como 'mapa mental' ou brainstorming [...]". A partir deste momento, como denotado pela Figura 1, a seguir, cada estudante tomou um caminho para oferecer, através do desenho de moda, a sua interpretação ao tema específico (final). 
Figura 1 - Brainstorming de um dos encontros do grupo de pesquisa.

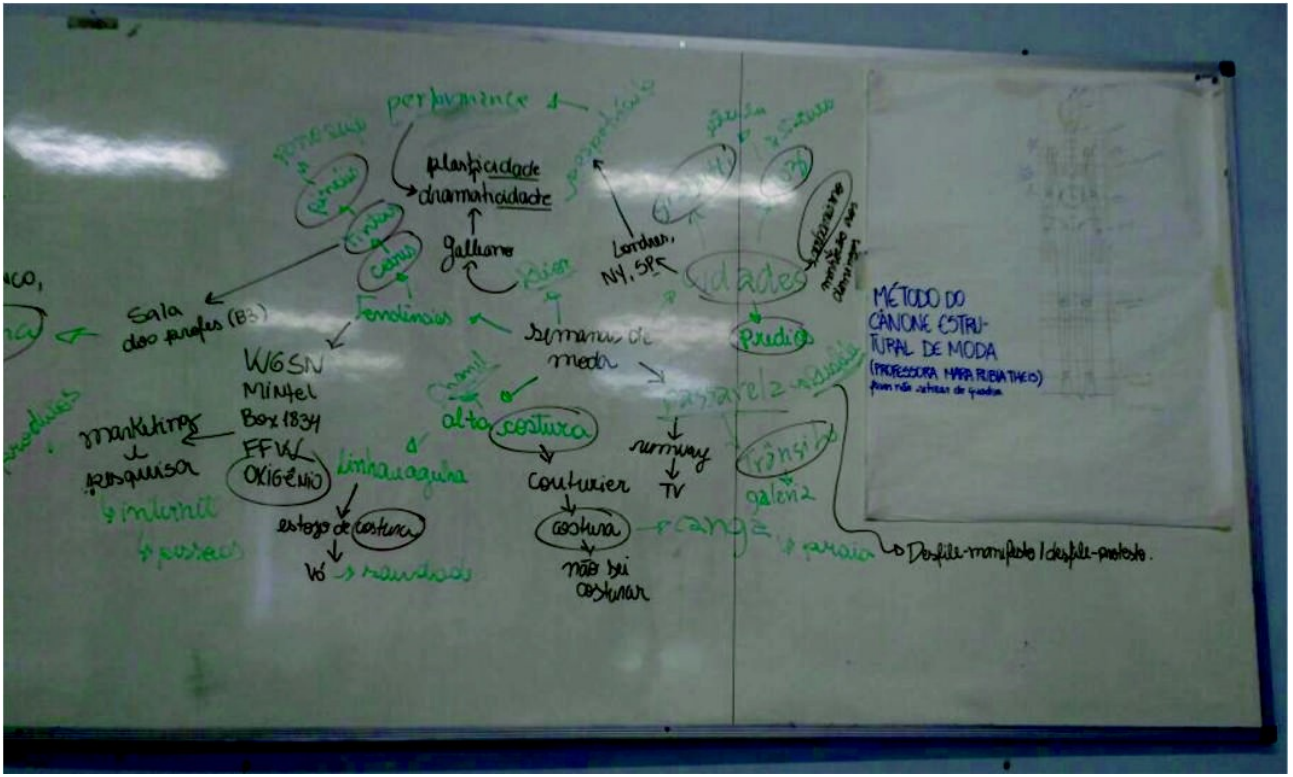

Fonte: acervo do grupo de pesquisa "Ilustração de moda avançada".

O tema específico escolhido através do brainstorming, deu origem ao briefing que cada estudante do grupo de pesquisa usou para desenvolver, sem acompanhamento direto ou supervisão dos professores, um painel de inspiração. O briefing, pode ser compreendido, segundo Renfrew e Renfrew (2010, p. 140), como uma

[...] proposta delimitação ou definição de conceito. Independentemente do seu nome, a atividade e o processo são os mesmos. Comece perguntando-se o que irá mostrar suas habilidades e criatividade da melhor forma. Alguns estudantes vêem essa fase [...] como ideias vagas ou irrealistas, pensando em fazer sua maior asserção pessoal [...]. Sem reflexão, pesquisa e muito trabalho, isso não irá funcionar. A criatividade na moda existe dentro de um contexto - e para a coleção [de moda], você cria seu próprio contexto, dentro de seu briefing [...].

Briefing em mãos, a próxima etapa estava na construção do painel de inspiração que, também pode receber o nome de painel conceitual. O painel de inspiração consiste, ainda segundo Renfrew e Renfrew (2010, p. 160), em uma "compilação de materiais de pesquisa, imagens, cores, tecidos e croquis, agrupados para comunicar visualmente uma ideia ou tema de produto."

Sem o objetivo de ocupar muito do tempo disponível dos estudantes, visto que o perfil destes, em ambos os cursos técnicos (em Produção e Design de moda e em Vestuário) é de estudante-trabalhador, que se sustenta ou contribui para o sustento da sua respectiva unidade familiar; os painéis de inspiração foram resumidos à captura e seleção de imagens, bem como sua breve manipulação digital.

Com o painel de inspiração pronto, cada estudante partiu para o desenvolvimento de seu desenho de moda, ora buscando a orientação dos professores para detalhes ou técnicas, ora construindo o seu caminho no desenho de maneira autônoma e experimental. Os desenhos finalizados que resultaram dos temas específicos (e de seus respectivos briefings) foram apresentados regularmente durante os encontros do grupo de pesquisa - que esteve em atividade no período de agosto de 2016 até julho de 2017. A Figura 2, a seguir, ilustra como ocorreram, 
quinzenalmente, as etapas de desenvolvimento do trabalho do grupo de pesquisa nesse período.

Figura 2 - Etapas do desenvolvimento do trabalho do grupo de pesquisa

A. Pesquisa prévia sobre assuntos, pautas, referências em moda e design

Estudantes, em conjunto ou individualmente

J. Desenho de moda

Cada estudante, individualmente

I. Painel de inspiração
Cada estudante, individualmente

H. Briefing sobre o tema específico Em acordo com o grupo

G. Tema específico

Em acordo com o grupo
B. Encontro quinzenal

Professores e estudantes

C. Apresentação da pesquisa prévia Estudantes, em conjunto ou individualmente

D. Seleção de temas e discussões Professores e estudantes

E. Temas acolhidos

Professores e estudantes

\section{F. Brainstorming}

Professores e estudantes

Fonte: elaborado pelo grupo de pesquisa "Ilustração de moda avançada" (2017).

A Figura 3 apresenta o ciclo quinzenal com as etapas do trabalho desenvolvido pelo grupo de pesquisa. Dela, destaca-se o próprio encontro (B), no qual a criatividade e a imaginação eram assuntos recorrentes. Quão grande foi o interesse despertado nesses assuntos que, com a contribuição expressiva de um dos professores do grupo, chegou-se ao conhecimento da teoria vigotskiana. Logo, nas discussões realizadas, surgiu a intenção de traçar um prisma entre tal teoria e sua possível contribuição ao desenho de moda. Assim, pergunta-se: A perspectiva vigotskiana sobre a relação entre a imaginação e a criatividade pode trazer contribuições para o desenho de moda?

Para responder ao que é proposto e, como os desenhos gerados foram muitos, devido aos muitos temas e ao número de estudantes no grupo de pesquisa, para apresentação neste artigo optou-se por um sorteio que contemplou as estudantes Lesley Ramos e Letícia Vendramini.

Os desenhos das estudantes são apresentados e analisados na quarta parte deste artigo, que, por sua vez, é composto por cinco momentos, sendo eles: uma breve contextualização da teoria vigotskiana e sua abordagem a respeito da imaginação e da criatividade (2), que será abordada a seguir; a conexão entre desenho de moda, criatividade e vivências (3); a metodologia realizada para a atividade pedagógica (4); a análise dos desenhos de moda selecionados com base nos estudos do grupo de pesquisa (5); as considerações finais (6); e as referências (7). 


\section{Vigotski: criatividade e imaginação}

Esta pesquisa aborda a perspectiva de Lev S. Vigotski que nos legou uma base teórica sobre o desenvolvimento humano, de forma distinta ao que até então havia sido compreendido pela psicologia. Vigotski foi um bielorrusso de muito talento, educador, psicólogo, pesquisador, dedicado aos estudos e à compreensão do processo de humanização. Buscou entender as condições e determinantes da formação da mente humana, sobretudo sobre a influência social.

$\mathrm{Na}$ perspectiva vigotskiana, não há dúvidas de que criatividade e imaginação são indissociáveis. Fato é tal que, para Vigotski $(2009$, p. 14) “[...] na verdade, a imaginação é base de toda atividade criadora, manifesta-se, sem dúvida, em todos os campos da vida cultural, tornando possível a criação artística, a científica e a técnica." Para o autor, a imaginação resulta das vivências e das experiências sociais de cada indivíduo, desde as lembranças mais simples da vida cotidiana, até as memórias mais complexas - e essa combinação auxilia o indivíduo a formar um conjunto de possibilidades, entendendo-se a sua capacidade combinatória. A imaginação, por si só, aparece na perspectiva de Vigotski como parte fundamental para se "criar algo novo", um aspecto que envolve também a imitação e a modificação.

Vigotski (2010) aponta que as vivências e experiências formam uma constante de criação, ao passo que,

A vida se revela como um sistema de criação de permanente tensão e superação, de constante criação e combinação de novas formas de comportamento. Assim, cada ideia, cada movimento e cada vivência são uma aspiração de criar uma nova realidade, um ímpeto no sentido de alguma coisa nova (VIGOTSKI, 2010, p. 462).

Ao ímpeto de criação, o autor associa os aspectos vivenciados pelo indivíduo enquanto ser social e cultural, aspectos estes que perdurarão durante a vida adulta e poderão resultar em atos criativos mais seguros. É inegável, a Vigotski (2009; 2010) enquanto estudioso da mente infantil, que o processo de criatividade e de imaginação seja, portanto, construído desde os primeiros anos de vida do indivíduo. E, cabe então, nesse sentido, aos pais e aos professores oferecerem muitas e diversificadas experiências aos estudantes - que, assim, terão sua criatividade e sua imaginação estimuladas - para que conheçam mais e mais do mundo onde habitam e de tudo ao seu redor.

Ao estímulo da criatividade e da imaginação, somam-se os sentimentos gerados a partir das experiências do indivíduo. Tais sentimentos constituem-se, para a moda, em fonte de criação, especialmente no que se relaciona ao desenho. Portanto, é válida, pedagogicamente, a retomada destes, bem como das experiências do estudante, para o bom desenvolvimento dos desenhos de moda. Sobre os sentimentos e sua relação com a imaginação, Los et al. (2015, p. 222) acrescenta:

\footnotetext{
A imaginação é resultante de experiências sociais, culturais, que geram sentimentos. Quando uma criança nasce já está participando de atividades culturais possibilitando a imaginação, pois as experiências de vida remetem a um signo, que pode inspirar sentimentos e a combinação destes fatores impulsionam a criatividade por meio da imaginação.
}

Para Vigotski (2010), os sentimentos e as sensações possuem uma relação próxima com a estética. Em toda criação, acredita-se, está intrínseca a estética, pois, afinal, toda forma de criação resulta de uma série de escolhas estéticas a respeito de materiais, formas, texturas, cores, entre outros aspectos. Renfrew e Renfrew (2010, p. 160) corroboram a visão da moda sobre a estética ao defini-la como um "conjunto de princípios dominantes na obra de um determinado designer ou 
artista. No design de moda, isso significa o modo pelo qual um estilista usa tecido, corte, escala, cor, textura e referências." Nesse sentido, essas escolhas são usadas mutuamente para contagiar os indivíduos com novos e diferentes sentimentos, que estão ligados com o sentido que cada um atribui ou atribuirá para aquela dada criação vivenciada, observada ou construída. Na visão de Vigotski (2010, p. 333), essa estética compreende-se em:

[...] uma atividade construtiva sumamente complexa, que é realizada pelo ouvinte ou espectador e consiste em que viva com as impressões externas apresentadas, o próprio receptor constrói e cria o objeto estético para o qual já se voltam todas as suas posteriores reações.

$\mathrm{Na}$ teoria vigotskiana, a criação surge das conexões entre as escolhas estéticas, as experiências e vivências do indivíduo, e os sentimentos com elas relacionados. Para o autor, estudioso da mente infantil, e, como citado anteriormente, pouco importa se a criação é física ou uma construção da mente, ou ainda um sentimento: tudo o que é novo pode ser considerado uma criação. A seguir, será explorada a relação entre criação e desenho segundo a visão de Vigotski.

\subsection{Vigotski: criação e desenho}

Todos os indivíduos, desde pequenos, aprendem a desenhar por meio da imitação, segundo a teoria vigotskiana. Ao observar o outro e se utilizando de fragmentos da sua memória, o indivíduo, estudante ou não, pode desenvolver e criar seu próprio jeito de desenhar - que, no universo da moda, recebe o nome de desenho autoral. Este desenho contém os traços únicos, característicos de seu autor e é, também, fruto da tradução de sua personalidade. Para Nunnelly (2012), o desenho autoral constrói-se como resultado de um estilo pessoal, que é atributo essencial para qualquer indivíduo que aspire à ilustração de moda e seus caminhos.

Além de memórias e sentimentos, há indivíduos que buscam inspiração em imagens ou construções imagéticas, ou mesmo textos, fotografias e vídeos. E, desde cedo, é "[...] a partir do contato com uma imagem ou com um livro, [que] a criança já pode vivenciar experiências significativas para seu processo imaginativo" (LOS, et al, 2015, p.223). Nesse processo, cada indivíduo desenvolve sua imaginação de forma peculiar, que, conhecidamente, não nasce do nada, olhando-se para uma parede branca, por exemplo. A imaginação pode se apoiar, por exemplo, na fantasia para, então, suscitar a criatividade.

$\mathrm{Na}$ perspectiva que Vigotski (2009) oferece, a fantasia consiste em etapa essencial no processo de imaginação e, consequentemente, de criatividade, pois é por meio dela que o indivíduo consegue resgatar experiências armazenadas na memória, e recriá-las em sua imaginação, recombinando fatores e criando algo verdadeiramente novo. Podemos dizer que as crianças possuem certa vantagem nesta parte, pois, quando incipientes, elas são mais dotadas de fantasia do que os adultos. Não raro, na vida adulta, é possível perceber a fantasia minimizada pelo senso de realidade que pode ser restringida pela auto censura. Para Jenny (2014, p. 69), o que ocorre é que:

Muitas pessoas param de desenhar quando veem que o resultado não corresponde às expectativas de realismo que elas mesmas se impõem. Para a maioria, isso acontece entre os oito e os doze anos de idade - com exceção daqueles que se consideram talentosos [...].

É possível notar, desse modo, que ocorre um certo desinteresse no processo de desenhar no final da infância e no início da adolescência, advindo parte da autocrítica, como exposto por Jenny (2014), e parte pela falta ou inadequação de estímulos para o desenho que a criança recebeu (ou 
deveria ter recebido) dos adultos mais próximos, conforme aponta Vigotski (2009). Regularmente, tal interrupção também é dada pela errônea crença de que, em determinada idade, ou o indivíduo deve apresentar uma maturidade em seu desenho, ou deve abandonar a linguagem infantil. Jenny (2014, p. 7) ainda acrescenta que:

[...] Todos nós já fomos crianças, mas ao chegarmos à adolescência ou à vida adulta, nosso sistema de valores muda e deixamos de apreciar a ingenuidade dos desenhos que fazíamos durante a infância. Os processos racionais começam a impregnar nosso traço e, com isso, a linguagem infantil é deixada para trás [...].

Ao estudar a perspectiva vigotskiana, Los et al. (2015) adiciona que tal interrupção na linguagem infantil do desenho pode acontecer pela concepção equivocada, por parte dos professores, de que a imitação realizada pela criança não possui valor.

Muitas vezes a imitação ainda é vista como algo negativo no campo das artes dentro da escola. Mas, para Vigotski, a imaginação faz parte do processo intelectual em que a criança é influenciada pelo que vê e imita, agindo sob a influência do social, obtendo parâmetros ou pontos de partida, que dão início ao seu processo de criação. (LOS, et al, 2015, p. 205).

Pode-se dizer, então, à luz da teoria vigotskiana, que a imitação faz parte do ato de aprender no processo de internalização dos conhecimentos, o que contribui diretamente para a imaginação com consequências para a atividade criativa. Conforme Vigotski (2009), a imaginação é uma função psicológica superior muito importante, que é constituída ao longo da vida, no decorrer do desenvolvimento de cada indivíduo, e que depende das relações sociais vivenciadas. tudo o que foi internalizado pode ser usado para o processo dialético entre imaginar e criar. $E$, na moda, todas as experiências vivenciadas pelo indivíduo enquanto estudante, futuro estilista ou designer, poderão ser utilizadas para que ele crie coleções mais ousadas, funcionais e criativas. No desenho de moda a criatividade é essencial, pois só a partir dela o estudante consegue se libertar de desenhos estereotipados e criar autoralidade.

\section{Desenho de moda: lugar de criatividade e de vivências}

O desenho de moda ocorre em diferentes âmbitos na vida do estudante e do profissional da área, seja ele estilista ou designer. Ocorre para comunicar ideias, para registrar um determinado produto, para salvar insights ${ }^{1}$ do esquecimento e, ainda, pode ocorrer como forma de apreciação, de beleza e de conceito, quando é desenvolvido com finalidade artística, não meramente comercial. O desenho de moda, pode, assim, ser usado para diferentes funções: esboço, desenho técnico, desenho de coleção, ilustração de moda, entre outras.

As funções do desenho de moda variam conforme a época, a tecnologia disponível, a estética em voga na sociedade e o contexto em que se insere - acadêmico, artístico, empresarial, industrial. Para Renfrew e Renfrew (2010), por exemplo, há uma ampliação da função do desenho quando trata-se da atual indústria da moda. A saber:

[...] o desenho tornou-se um termo muito mais amplo na indústria da moda, que requer desenho técnico, quadro de coleção e documentos de especificação. O desenvolvimento de vários softwares permitiu aos alunos de moda reproduzir uma variedade de técnicas e processos padrões da indústria ao apresentar ideias de moda e coleções (RENFREW; RENFREW, 2010, p. 147).

$\mathrm{Na}$ apresentação de tais ideias, assim como em outros momentos, qualquer estudante de

1Pode-se entender, nesse contexto, insight como uma ideia rápida e fugaz. 
moda pode perceber no desenho uma etapa importante no seu desenvolvimento, que influencia a sua compreensão sobre estética e design. Não raro, essa compreensão muda conforme são absorvidas novas informações, novas referências imagéticas e novas linguagens. $O$ próprio desenho, cabe citar, é uma dessas linguagens que alimentam - e retroalimentam - o estudante, que anseia por se desenvolver na área artística ou da moda, ou qualquer outra área que utilize o desenho como recurso, em especial, aqueles que estão vivenciando ou saindo da fase da adolescência.

Para Vigotski (2009, p. 117),

[...] o desenhar possui um enorme sentido cultivador; quando, [...] as cores e o desenho começam a dizer algo para o adolescente, este começa a dominar uma nova língua, que amplia sua visão de mundo, aprofunda seus sentimentos e transmite-lhe, na língua de imagens, o que de nenhuma outra forma pode ser levado até a consciência.

A língua de imagens da teoria vigotskiana, descoberta aos poucos pelo estudante adolescente, é também parte da formação de seu repertório estético na vida adulta. Tal repertório é de interesse da moda, que, ao propor a construção e desconstrução de linguagens, estimula o resgate das referências imagéticas de outrora, assim como das informações memorizadas e das situações internalizadas. Então, o "eu", na moda, tornar-se-á o autoral no desenho de moda.

Tal autoralidade no desenho de moda não ocorre longe da dimensão das experiências vivenciadas pelo estudante. São elas que, segundo a perspectiva vigotskiana, poderão subsidiar um indivíduo mais criativo no futuro. Para corroborar, Los et al. (2015, p. 206-207), acrescenta que "para ser muito criativa, a pessoa deve ter tido acesso a inúmeras experiências anteriores, com diferentes materiais, processos e atividades, para que a partir dessas experiências brotem atividades criadoras de sua mente."

Vê-se, então, que a relação entre a criatividade e as experiências vivenciadas pelo estudante pode gerar desenhos de moda mais criativos. E, é na fase da adolescência, que esse potencial criativo para o desenho, ultrapassa o simples fazer da imaginação criadora. Conforme Vigotski acrescenta (2009, p. 117),

[...] para o adolescente já não basta uma atividade de imaginação criadora; ele não se satisfaz com um desenho qualquer para a contemplação de sua imaginação criadora e precisa adquirir habilidades e conhecimentos especiais e profissionais. [...] Somente cultivando o domínio dos materiais podemos pô-lo no caminho certo do desenvolvimento do desenhar nessa idade.

Adquiridas as habilidades e os conhecimentos necessários, o estudante adolescente pode se sentir seguro para superar o estado da imaginação. Consequentemente, ele pode tornar-se um adulto confiante e um profissional corajoso diante de desafios criativos, como encarar a folha em branco, por exemplo. Segundo Morris (2009), este é exatamente um dos grandes entraves para aqueles que almejam o desenvolvimento artístico:

Não há dúvida de que uma das coisas mais difíceis para um artista é encarar uma folha em branco. A perspectiva de tirar novas ideias do nada e chegar a uma solução artística original é estressante. Por isso é importante cultivar uma base de conhecimentos por meio da qual as ideias criativas possam se desenvolver (MORRIS, 2009, p. 13).

A base de conhecimentos a qual se refere Morris (2009) é somada com as habilidades adquiridas pelo estudante e com as experiências por ele vivenciadas para que forme, então, seu potencial criativo. Quanto mais vivências, quanto mais conhecimento e mais treinar suas 
habilidades, mais ele superará o campo da relés imaginação e da mera fantasia - e, possivelmente, maior será sua capacidade de atribuir criatividade ao que desenha. Para Jenny (2014), isto implica também em um aumento na compreensão e na produção da linguagem das imagens que o estudante internaliza, interpreta e elabora.

Assim, no desenho de moda, as imagens construídas através da linguagem proposta pelos futuros estilistas e designers tornam-se expressão de seu potencial criativo na medida em que, ao longo da vida e especialmente na fase da adolescência, estes adquirem experiências, vivências, conhecimentos e desenvolvem habilidades. Portanto, como próprio lugar de criatividade e de vivências, o desenho de moda é, enfim, linguagem do potencial criativo do estudante de moda.

\section{Metodologia}

Em Jaraguá do Sul, cidade de Santa Catarina, conhecida como região do médio vale do Rio Itapocú, mais precisamente no Instituto Federal de Santa Catarina, IFSC, unidade centro, fora realizada uma intervenção pedagógica com adolescentes que estudam nos cursos técnicos de Produção e Design de Moda e de Vestuário. Alguns dos estudantes de ambos os cursos participaram do grupo de pesquisa, cujo nome determinou-se "Ilustração de moda avançada", criado pela própria instituição, que teve como intuito estudar o desenho e a ilustração no contexto da moda.

Composto por dois professores formados em design de moda, que atuam em ambos os cursos, e com mais dez estudantes, o grupo sugeriu a ideia de realizar uma intervenção pedagógica para responder a questão: A perspectiva vigotskiana sobre a relação entre a imaginação e a criatividade pode trazer contribuições para o desenho de moda?

A prática pedagógica ocorreu da seguinte forma: os estudantes se reuniam para selecionar um tema e fazer um painel de inspiração, e, em seguida, um desenho de moda sobre o tema que era escolhido por meio de brainstorming. Vários desenhos de moda foram criados, e, para este artigo, alguns foram selecionados através de sorteio - os desenvolvidos por Lesley Ramos e os de autoria de Letícia Vendramini. Depois foram selecionados, também por meio de sorteio, qual o tema específico criado pelo grupo de pesquisa que deveria ser usado na construção da análise. 0 tema escolhido foi: "tramaticidade", que aqui representa a trama de prédios e construções nas grandes metrópoles do mundo.

As estudantes selecionadas trouxeram seus desenhos e painéis relativos a este tema e deuse início à análise, com base na teoria de Vigotski sobre imaginação e criatividade. As categorias de análise foram escolhidas, a priori, pelo grupo de pesquisa, e são: memorização/imitação e imaginação/criatividade. Parte-se, a seguir, para a então análise dos desenhos visando observar e levantar em que aspectos houve o uso das categorias selecionadas.

\section{Análise dos desenhos de moda}

Analisa-se como ocorreram os processos de imaginação e criatividade nas adolescentes que fizeram parte da prática pedagógica, fazendo ligação com os métodos e processos usados pelas estudantes, e o uso do painel de inspiração como norteador. A análise parte de um tema gerador instigante, que foi escolhido pelo grupo de pesquisa, o tema "tramaticidade", que envolve muitos fatores, como a trama das cidades, o emaranhado de prédios e carros, a malha viária; e pode fazer surgir leituras diferenciadas de acordo com a experiência de cada estudante envolvido e de cada professor também. Ao serem analisadas as produções artísticas e o método utilizado pelas 
adolescentes para realizar os desenhos, definiram-se as seguintes categorias:

Memorização e Imitação: são as características que, normalmente, adolescentes utilizam e que tem relação direta com o painel de inspiração, pois dele memorizam-se aspectos relevantes, e se reconstroem novas representações, formando a criação. Levando em consideração que a imitação não é cópia, é resultado da criação baseada nas experiências vivenciadas.

Imaginação e Criatividade: a imaginação vista aqui como um processo interno que recombina imagens do que é observado, a partir das experiências de vida. A criatividade, nesse aspecto, é o resultado do sentido atribuído à leitura da imagem, na qual se misturam as vivências de cada estudante com o que é visualizado, fazendo surgir a criação.

Figura 4 - Painel de inspiração "tramaticidade" da estudante Letícia Vendramini

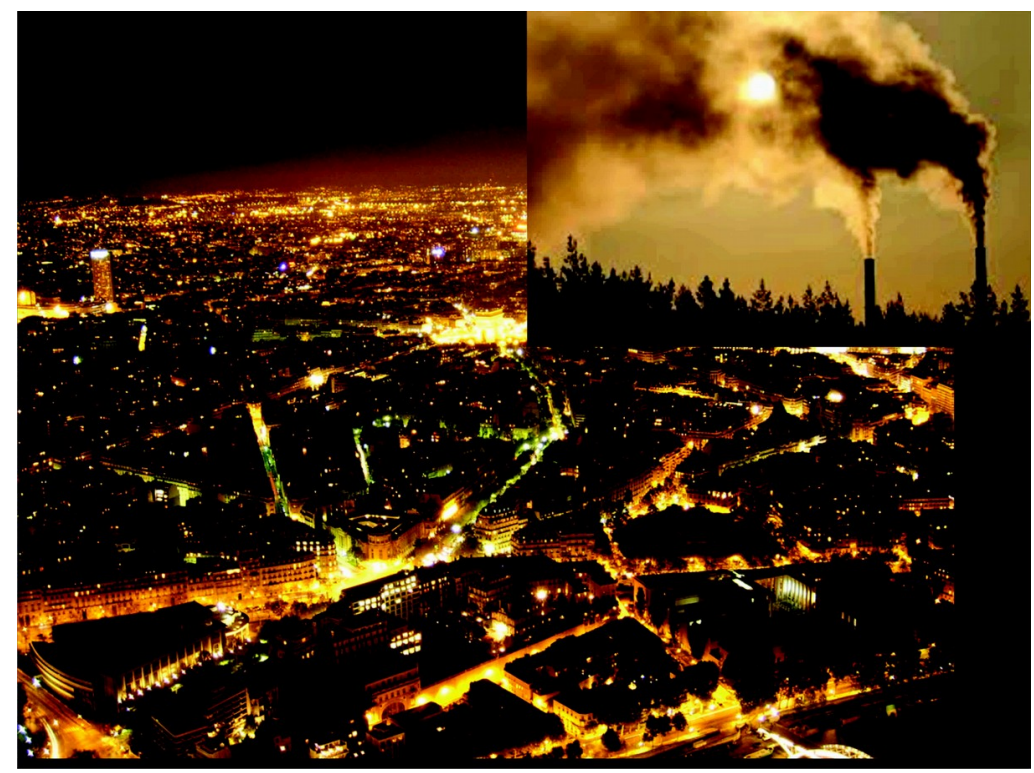

Fonte: arquivo pessoal da estudante (2017).

A estudante Letícia Vendramini, de 18 anos, fez o desenho, a seguir, imaginando a "tramaticidade" como uma grande selva. Percebe-se o uso da fumaça como fundo, talvez tentando imitar a fumaça existente no painel de inspiração, porém, não da mesma cor e não da mesma tonalidade. Há um mar de fumaça cinza claro, com diferentes nuances, e que se contrasta com o branco da folha. Segundo Vigotski, (2009, p. 16) "todos conhecem o enorme papel da imitação nas brincadeiras das crianças. As brincadeiras infantis, frequentemente, são apenas um eco do que a criança viu e ouviu dos adultos." Percebe-se o quanto é útil o processo de imitação no aprendizado do desenho, pois, para que o estudante se aproprie de meios para desenhar algo novo ou com novas formas, ele precisa imitar o que viu. E para Vigotski (2009) essa imitação não é cópia, afinal, o estudante sempre estará reelaborando o que foi visto e ouvido, e reconstruindo esse saber, em algo novo. Ou seja, quando o vivenciado é reproduzido, ele passa por um processo de combinações de recordações vivenciadas que redimensionadas, transformam este ato vivenciado em algo novo.

No desenho, a estudante imagina uma mulher sobrevivente naquele mar de fumaça, com os cabelos presos, talvez em função do risco de contaminação, e com o rosto coberto por uma 
máscara cirúrgica, que the cobre as narinas. Este aspecto pode ter sido desenhado devido a sua lembrança de imagens da televisão e de redes sociais, imagens nas quais facilmente vêem-se metrópoles asiáticas, por exemplo, onde o uso de máscara é habitual. Isto reflete dada memorização. Conforme Vigotski $(2009$, p. 25$)$ por meio da narração de outrem pode-se imaginar estar onde nunca se esteve antes. "Neste sentido, a imaginação [...] transforma-se em meio de ampliação da experiência de um indivíduo porque, tendo por base a narração de outrem, ele pode imaginar o que não viu [...]". Os adolescentes e as crianças usam muito esse tipo de estratégia para aprender coisas que ainda não vivenciaram.

O desenho de memória é realizado com frequência por crianças e adolescentes, pois tratase de um período da vida no qual a memória é constantemente acessada para a expressão.

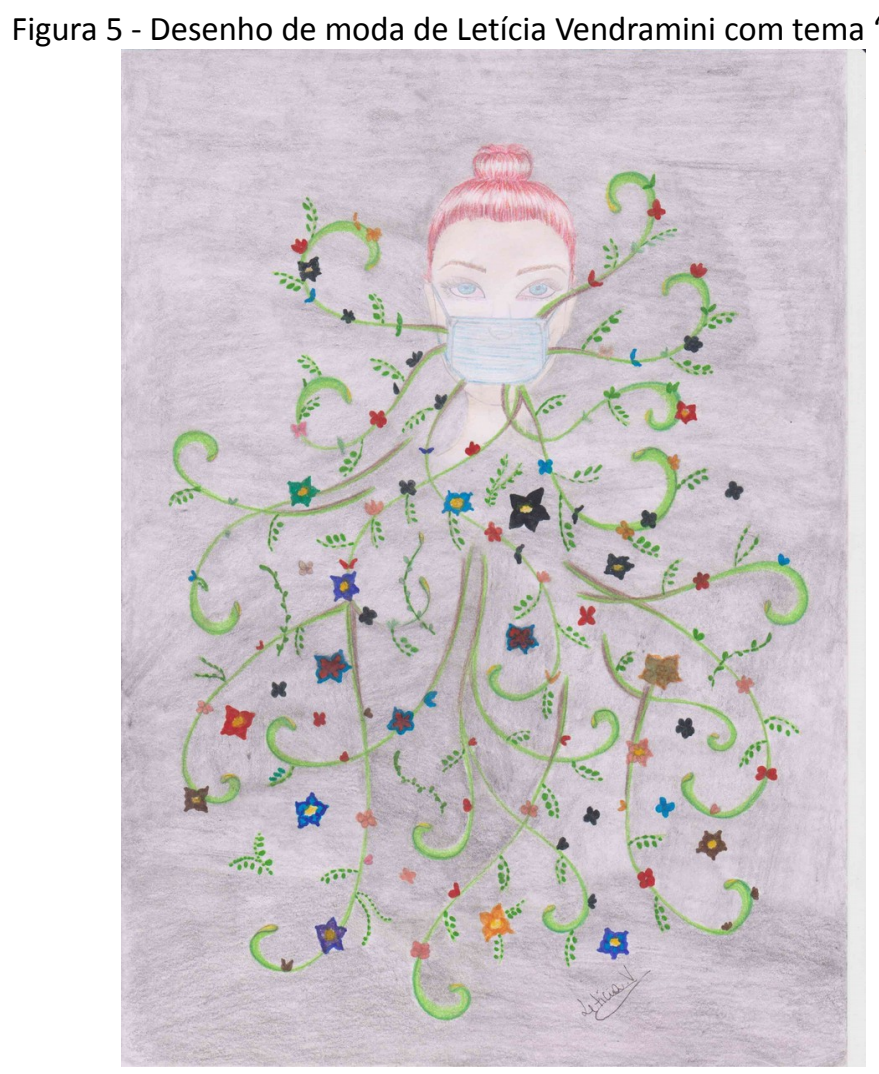

Fonte: acervo pessoal da estudante (2017).

Para Letícia Vendramini, em meio a esta selva de fumaça que são as metrópoles, ainda existe espaço para o verde, e para as flores, mesmo que poucas. É possível perceber isso pelas folhagens desenhadas abaixo do rosto humano. A estudante percebe a vida em meio a tramas citadinas: as plantas que estão na parte superior do seu painel de inspiração trouxeram lembranças de flores que ela teve contato em algum momento de sua vida. Afinal, as flores desenhadas não são imitação do painel de inspiração, e provavelmente são imagens contidas na memória da estudante.

Conforme Vigotski (2009, p.45), "à medida que a maturidade se aproxima, começa também a amadurecer a imaginação e, [...] nos adolescentes, [...], a potente ascensão da imaginação e os primeiros rudimentos de amadurecimento da fantasia unem-se." Então, os adolescentes, que já 
possuem mais experiências de vida, podem ser mais criativos do que as crianças de menor idade. Quando o tema imitação é abordado, percebe-se que a estudante vai além do ato de desenhar aquilo que está presente em seu painel de inspiração, pois para a estudante, cada imagem presente nele, remete a vivências e sentimentos já experienciados de alguma forma, buscados em sua memória. Portanto, para Letícia Vendramini, talvez a metrópole não seja o seu desejo de consumo, afinal remete a poluição, falta de ar puro, falta de natureza em abundância.

É possível observar que o seu desenho possui traços simples e criativos, representando bem a ideia da vida na "tramaticidade". Acrescenta Jenny $(2014$, p. 9) que, "[...] quando o assunto é desenhar, precisamos substituir a ideia de fazer alguma coisa do jeito 'certo' ou 'errado' pela ideia de experimentação. Essa é a lição que aprendemos com as crianças - não existe jeito certo nem errado de desenhar." Com olhos na afirmação de Jenny (2014), denota-se que cada estudante adquire o seu estilo próprio de desenhar, e que enquanto professores mediadores dessa prática, não convém julgamento sobre o que é certo ou o que é errado no desenho.

Ao desenhar as folhagens saindo da boca da mulher, percebemos que a estudante buscou expressar que nas metrópoles, a vida/natureza emerge de pequenas atitudes, mesmo que de discursos e falas sobre o assunto. É possível perceber que, para ela, é uma necessidade humana ter a natureza perto de si, mesmo que em pequenos detalhes. Através de sua criação, a estudante conseguiu transmitir sua idéia a respeito do tema e trouxe a imitação, a imaginação e a criatividade como elementos de seu desenho de moda.

Ao serem abordados os desenhos da estudante Lesley Ramos, de 17 anos, é possível deparar-se com um painel de inspiração cheio de formas, com prédios diferenciados, conforme apresenta a Figura 6, abaixo.

Figura 6 - Painel de inspiração "tramaticidade" da estudante Lesley Ramos

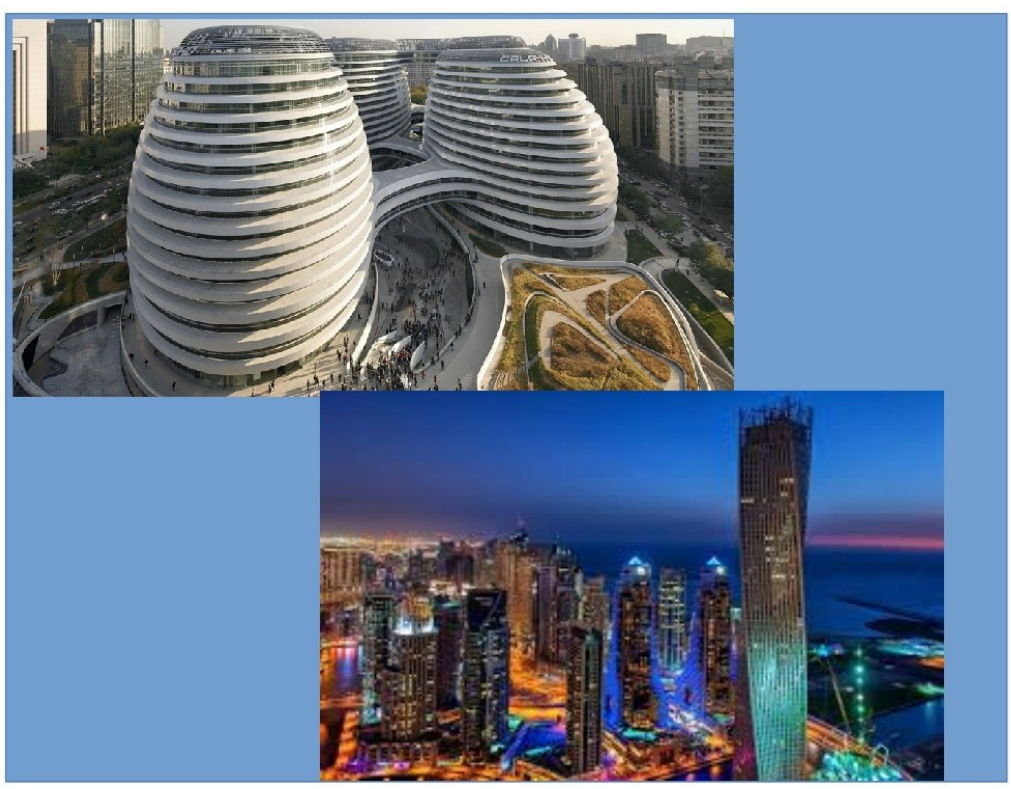

Fonte: acervo pessoal da estudante (2017).

O painel de inspiração, Figura 6, deu origem ao desenho de moda de Lesley Ramos, Figura 
7. Em seu desenho, a estudante expressa as formas sinuosas dos prédios arredondados que existem no painel de inspiração por meio do vestido volumoso, arredondado e com armação encorpada. Talvez lembrando um sonho de criança, Lesley Ramos desenha uma mulher delicada, que se assemelha a uma princesa, usando vestido vermelho e preto, com cores extraídas do painel de inspiração. O vestido é escondido por uma metrópole, com seus prédios, luzes, cores e armações, como se fosse engolido pela enaltecida cidade.

Segundo Vigotski (2009, p. 44),

[...] a obra da imaginação infantil diverge forte e nitidamente da experiência do adulto, o que permite chegar à conclusão de que a criança vive mais tempo num mundo fantasioso do que no mundo real. Ainda, são conhecidas as impressões, as alterações da experiência real, o exagero e finalmente, o gosto pelos contos e histórias fantásticas, característicos da criança.

Percebemos claramente, que Lesley está na fase de transição entre o fim da adolescência, pois sua escolha em usar uma mulher que se assemelha a uma princesa, com um vestido rodado, expressa certo romantismo contido nos contos infantis. Para Jenny (2014, p. 135), "o significado de um desenho é revelado tanto durante seu processo de construção como quando é visto depois de concluído. As sugestões despertam lembranças e provocam nossa imaginação." Nesse desenho, a mulher transmite delicadeza a um tema que remete, facilmente, frieza, afinal, a "tramaticidade" aborda metrópoles com suas tramas de prédios, emaranhados de arames e estruturas de ferro.

Figura 7 - Desenho de moda de Lesley Ramos com tema "tramaticidade"

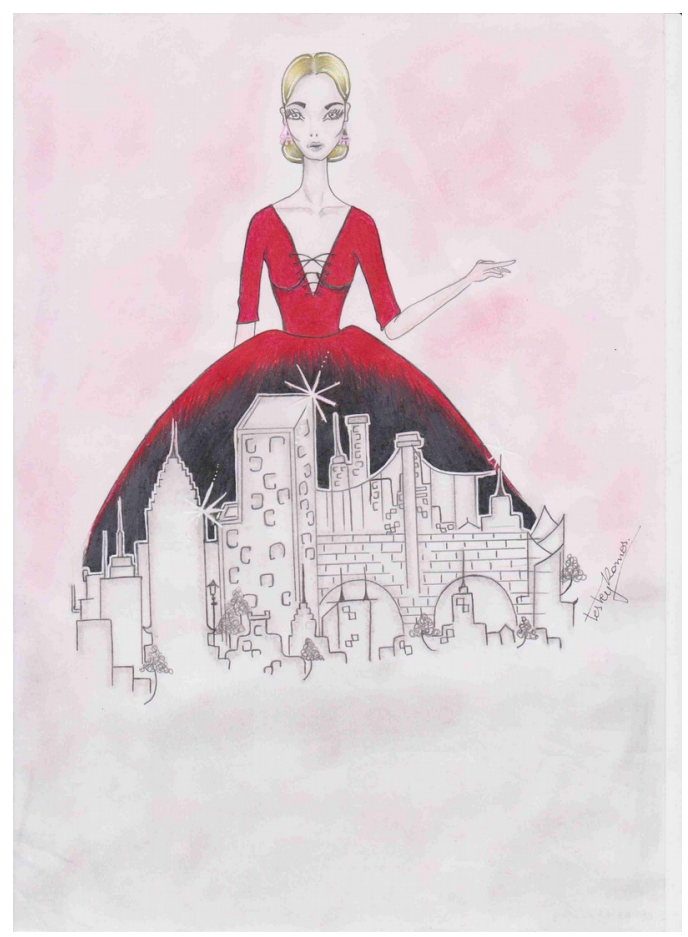

Fonte: acervo pessoal da estudante

Conforme observa-se na Figura 7, o desenho da metrópole lembra um vilarejo antigo, ou uma cidade da idade medieval, onde os vestidos usados eram semelhantes ao que a estudante desenhou. Nas aulas de artes e história da indumentária os estudantes relembram esses assuntos 
já estudados, talvez uma dessas aulas tenham contribuído para que Lesley Ramos imaginasse essas referências, e criasse algo novo. Para Vigotski (2009) a medida em que o adolescente cresce e vai se tornando adulto, sua imaginação e criatividade tendem a ter um declínio, se não forem adequadamente estimulados, evidentemente. A criatividade se torna casual, afinal, o adulto vive muito mais no mundo concreto e real, do que no mundo imaginário. Mas, o autor reforça a idéia de que para ter criatividade não é necessário ter dom, e sim ter estímulo. Assim, incitar a imaginação e a busca pelo retorno ao pensamento subjetivo e fantasioso, pode contribuir significativamente para o aumento da criatividade.

\section{Considerações finais}

Ao se propor responder se o desenho de moda pode ser analisado sob a perspectiva vigotskiana, em especial sob as considerações que Vigotski $(2009 ; 2010)$ faz à imaginação e à criatividade, o grupo de pesquisa "Ilustração de moda avançada" não poderia ter obtido maior sucesso. Não só o fez, mas deu vez à compreensão de que há instigantes caminhos que se cruzam entre o que é proposto pelo autor e o desenho de moda.

Ao serem analisados os desenhos de duas das integrantes do grupo de pesquisa, as estudantes Lesley Ramos e Letícia Vendramini, foi possível denotar relações diretas entre memorização, imitação, criatividade e imaginação. Ao solicitar que as estudantes produzissem desenhos de moda com base em painéis de inspiração, cujo tema era decidido em grupo com professores e outros estudantes, pôde-se vislumbrar como cada uma utilizou de experiências vivenciadas e sentimentos para ler os respectivos painéis e deles criar algo novo. O potencial criativo existente em tal ato reverberou na forma como cada uma "leu a linguagem das imagens" presentes nos painéis e produziu "a linguagem do desenho" - do seu desenho, único e autoral.

A forma como as estudantes introduziram autoralidade no desenho de moda ocorreu ao encarar o medo da folha em branco e vencê-lo. Elas o fizeram criativamente, pois, segundo a perspectiva vigotskiana, souberam resgatar de memórias e de experiências vivenciadas aquilo que vincularam ao tema "tramaticidade", conforme o proposto na prática pedagógica em questão, e, também, souberam transpor tais relações para a estética e o design no desenho de moda. Instigadas pelos adultos, neste caso, os professores, as adolescentes construíram suas próprias linguagens para o tema, sendo encorajadas e estimuladas constantemente para que o fizessem.

Aos professores coube o desenvolvimento de habilidades e o fornecimento de conhecimentos tais que subsidiaram as estudantes e as fizeram confortáveis diante do desenho. Dessa maneira, as adolescentes sentiram-se mais seguras e mais livres no ato de desenhar, o que repercutiu no engajamento das mesmas no grupo e em um desenho de moda mais criativo. Resguardando com cuidado apontamentos, os professores mantiveram o grupo de pesquisa aberto para interpretações diversificadas dos temas propostos aos desenhos, bem como também ampliaram as possibilidades de compreensão sobre o próprio desenho por parte dos estudantes, ao estabelecerem - e reforçarem, continuamente - que, no desenho, não há certo ou errado, conforme já apontava Jenny (2014).

Isto não só aliviou os estudantes do medo de errar, mas estimulou o grupo a criar de forma mais autoral. A autoralidade, segundo Nunelly (2012), é fundamental para a formação do futuro estilista ou designer, pois ela poderá se tornar sua assinatura no mundo, e eles poderão exercer seu potencial criativo com domínio e com segurança. E, conforme a teoria vigotskiana, é exatamente na adolescência que começam as frustrações que poderão travar este futuro, este 
desenhar na vida adulta.

Imaginação e criatividade, por fim, denotaram-se campos férteis no desenho de moda e possibilitaram novas compreensões à luz da perspectiva vigotskiana. Ao passo que embutem fantasia, memorização, experiências vivenciadas e conhecimentos internalizados, a imaginação e a criatividade formam uma combinação única que torna o indivíduo potencialmente criativo. Se esse indivíduo for estimulado a revisitar e a reinterpretar essas recordações e essas vivências e, somado com isto, for provocado a desenvolver suas habilidades, poderá, sim, tornar-se mais um adulto significativamente mais criativo.

Muitos são ainda os caminhos entre a teoria vigotskiana e o desenho de moda. Para futuros estudos, está posta a contribuição do presente artigo. Sugere-se, a partir da leitura de mundo que o autor faz sobre o desenho na infância, a realização de estudos outros que tragam à luz o reflexo da imaginação e da criatividade no desenho de moda ao longo da vida adulta de estilistas e designers.

\section{Referências}

JENNY, Peter. Técnicas de desenho. São Paulo: Editora Gustavo Gili, 2014. Tradução de: Denis Fracalossi.

LOS, Vivian Andreatta et al. Processos de imaginação e criatividade na construção do desenho na infância à luz da perspectiva histórico-cultural. Revista Eletrônica Pesquiseduca, Santos, v. 7, n. 13, p.219-224, jan./jun. 2015. Disponível em:

<http://periodicos.unisantos.br/index.php/pesquiseduca/article/view/398/pdf>. Acesso em: 10 abr. 2017.

MORRIS, Bethan. Fashion Illustrator: Manual do ilustrador de moda. 2. ed. São Paulo: Cosac Naify, 2009. Tradução de: lara Biderman.

NUNNELLY, Carol A. Enciclopédia das técnicas de ilustração de moda. Barcelona: Editora Gustavo Gili, 2012. Tradução de: Márcia Longarço.

RENFREW, Colin; RENFREW, Elinor. Desenvolvendo uma coleção. Porto Alegre: Bookman, 2010. Tradução de: Daniela Fetzner.

VIGOTSKI, L. S. A. L. Imaginação e criação na infância: ensaio psicológico: livro para professores. São Paulo SP: Ática, 2009.

Psicologia Pedagógica. (Tradução de Paulo Bezerra). São Paulo, SP: Martins Fontes, 2010. 